\title{
Long range acoustic measurements of an undersea volcano
}

\author{
Kevin D. Heaney a) and Richard L. Campbell \\ Ocean Acoustical Services and Instrumentation Systems, Inc., 11006 Clara Barton Drive, Fairfax Station, \\ Virginia 22039 \\ Mirjam Snellen \\ Acoustic Remote Sensing Group, Faculty of Aerospace Engineering, Delft University of Technology, \\ The Netherlands
}

(Received 18 October 2012; revised 20 May 2013; accepted 28 May 2013)

\begin{abstract}
A seamount $8 \mathrm{~km}$ southeast of Sarigan Island erupted on 29 May 2010 and was visually observed. The recordings on two sets of hydrophones, operated by International Monitoring System (IMS) of the Comprehensive Test Ban Treaty Organization (CTBTO) are analyzed. Each array is a triplet of axial single hydrophones deployed as a $2 \mathrm{~km}$ triangle. Measurements of acoustic intensity for the path to the southern triplet are on the order of $6 \mathrm{~dB}$ lower than those received on the northern triplet. Temporal cross-correlation beamforming estimation is performed and the estimated arrival angles for the two arrays, $265^{\circ}$ and $267^{\circ}$ were consistent with the predicted geodesic arrival of $264.6^{\circ}$ and $267.8^{\circ}$, respectively. Cross-correlation between single phones on the northern and southern arrays reveals a peak at $266^{\circ}$, with a cross-correlation of 0.1 . Nx2D parabolic equation modeling predicts complete blockage due to seamount interaction along the geodesic path. Overprediction of the seamount blockage indicates that the 2D approximation is incorrect, and three-dimensional propagation must be used to explain the observations. This is demonstrated by the computation of the Adiabatic Mode Parabolic Equation Transmission Loss, which predicts a 5-10 dB lower reception at the southern site. (C) 2013 Acoustical Society of America. [http://dx.doi.org/10.1121/1.4818844]
\end{abstract}

PACS number(s): 43.30.Qd, 43.30.Ma [JAC]

Pages: $3299-3306$

\section{INTRODUCTION}

On 29 May 2010 an undersea volcanic eruption $8 \mathrm{~km}$ southeast of the island of Sarigan occurred (Snellen et al., 2011). Sarigan Island is a volcanic island in the central Mariana Islands, with a maximum elevation of $538 \mathrm{~m}$. As indication of the volcanic event, local fisherman observed a large plume cloud. A small tsunami was generated in the central Pacific (U.S. Geological Survey, 2010). Based upon bathymetry and local observations of a plume cloud, the eruption location was determined to be $145.790278^{\circ} \mathrm{E}$, $16.5889^{\circ} \mathrm{N}$.

In this paper, hydro-acoustic measurements taken on a pair of triplet arrays north and south of Wake Island deployed and monitored by the Comprehensive Test Ban Treaty Organization (DeGroot-Hedlin and Orcutt, 2001; Prior et al., 2012) are presented. The WGS- 84 geodesic paths from the volcano location to the two arrays are shown in Fig. 1 overlaid on the ETOPO1 bathymetry. The geodesic range from the seamount to the northern triplet is $2253 \mathrm{~km}$ (2224 km to the southern). There is significant geologic activity in the area, leading to the presence of many undersea mountains. Measurements presented in Sec. II reveal a partial blockage of paths to the south. It can be seen in Fig. 1, that the southern path does indeed intersect a very shallow seamount located near $17^{\circ} \mathrm{N}, 153^{\circ} \mathrm{E}$. In an effort to understand this blockage, two-dimensional (2D) Parabolic Equation (PE) modeling is performed to examine the extent

\footnotetext{
${ }^{\text {a) }}$ Author to whom correspondence should be addressed. Electronic mail: oceansound04@yahoo.com
}

of the predicted blockage. The predicted blockage from 2D propagation is over $40 \mathrm{~dB}$ greater than observed, raising questions of the adequacy of Nx2D propagation modeling to deepwater acoustic propagation in the presence of seamounts. The ability of 3D propagation to predict the observations is demonstrated with the application of a low-frequency hybrid Adiabatic Mode PE computation.

This paper is organized as follows. Hydro-acoustic measurements and signal processing results are presented in Sec. II. Section III contains parabolic equation modeling of 2D propagation in the 3D ocean, showing bathymetric blockage. The $3 \mathrm{D}$ adiabatic mode $\mathrm{PE}$ model is presented to show how 3D effects can explain the observations. Section IV is the summary and conclusion.

\section{HYDRO-ACOUSTIC MEASUREMENTS}

In an extensive effort to monitor the world oceans for undersea testing of nuclear weapons, the CTBTO has deployed a set of hydro-acoustic stations (DeGroot-Hedlin and Orcutt, 2001). These H-stations, usually deployed from mid-ocean islands, consist of a pair of triplet bottommoored hydrophones with real-time data feeds via a single cable back to the island. The station of interest for this paper is the Wake Island Station H11, with a triplet deployed to the north (H11N1-N3) and to the south (H11S1-S3) of Wake Island. The first northern triplet has its first hydrophone (H11N1) located at $19.713611^{\circ} \mathrm{N}, 166.891111^{\circ} \mathrm{E}$, and the southern triplets first hydrophone (H11S1) is at $18.508333^{\circ} \mathrm{N}, \quad 166.700278^{\circ} \mathrm{E}$. The nominal distance between elements in the triplet is $2 \mathrm{~km}$. Acoustic measurements are recorded at $250 \mathrm{~Hz}$ sample rate and transmitted 


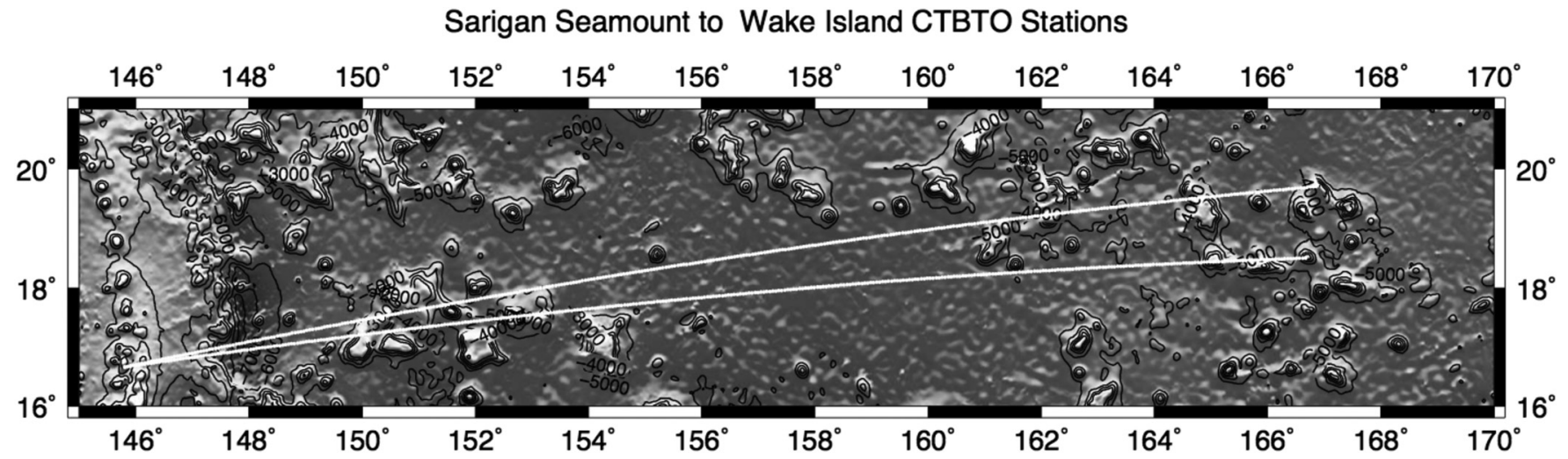

FIG. 1. Bathymetry (ETOPO1) and geodesic paths from Sarigan Seamount to CTBTO receivers North (H11N1-N3) and South (H11S1-S3) of Wake Island. There is interaction with a ridge at $148^{\circ} \mathrm{E}$. The southern path encounters a seamount at $152^{\circ} 24^{\prime} \mathrm{E}$. The receivers are triplets on moorings extending up into the water column.

back to CTBTO in Vienna for processing and identification of events (Hanson et al., 2001). The CTBTO provides a list of events (without classification) to all participating nations for further analysis and classification. The Sarigan volcano was recorded on both H11N1-3 and H11S1-3 and was identified as an event.
Four hours of acoustic timeseries, sampled at $250 \mathrm{~Hz}$, from the H11 station is examined. In the analysis the signal spectra, timeseries of peaks and cross-correlation beam responses will be examined. The single element spectrogram of four hours of data, beginning on 29 May 2010, at 0400 UTC, is shown in Fig. 2 for the first northern phone (H11N1, upper panel) and

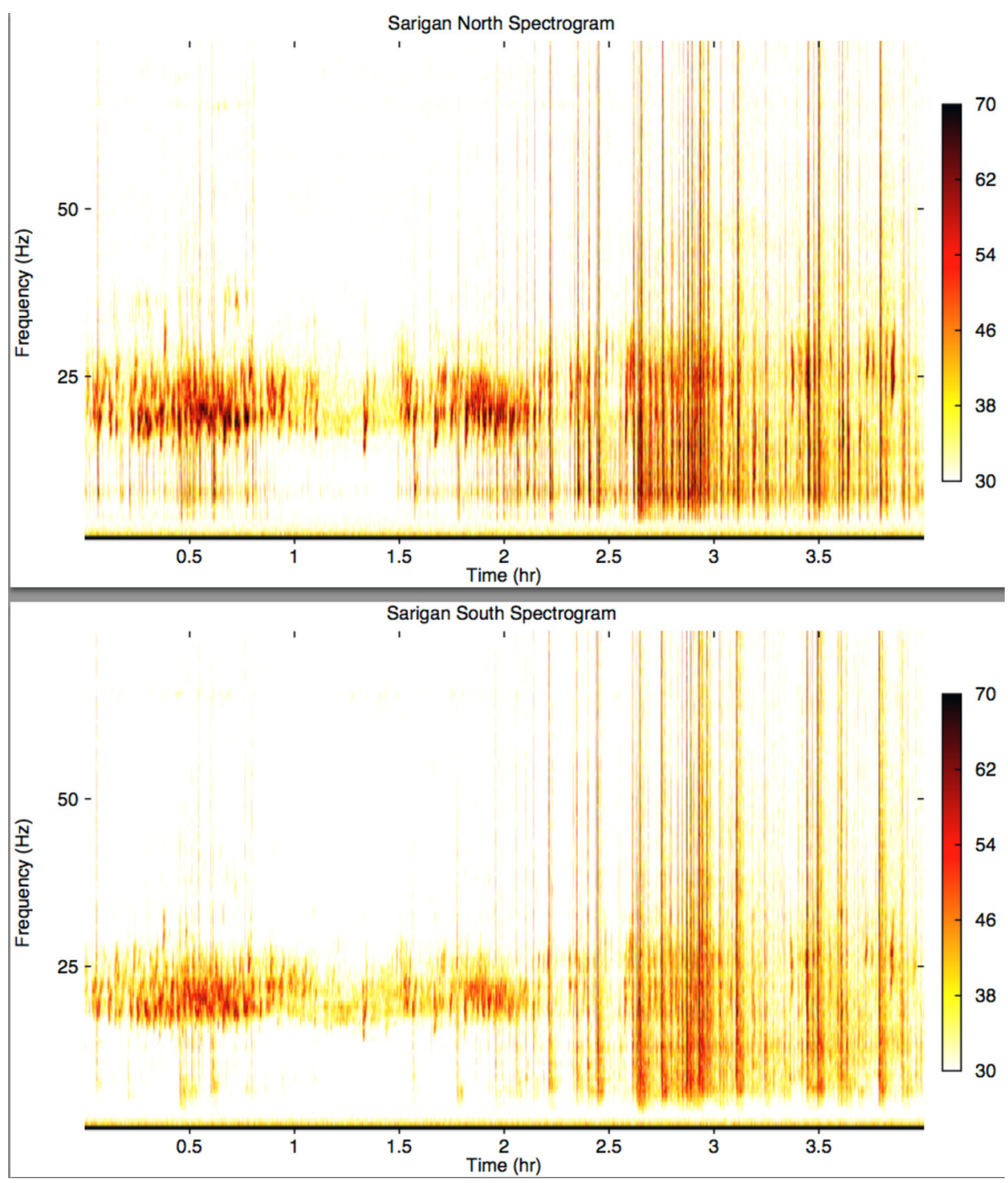

FIG. 2. (Color online) Four hour single element spectrograms from 29 May 2010, 0400Z for Wake Island Receiver (top) H11N1 and (bottom) H11S1, showing low frequency and broadband spike arrivals from the Sarigan Seamount volcano eruption. The $18-25 \mathrm{~Hz}$ energy is approximately $10 \mathrm{~dB}$ higher on the northern phone compared to the southern. Note the significant correlation between the two phones, which are separated by $138 \mathrm{~km}$. 
the first southern phone (H11S1, lower panel). The processing steps include removing the DC offset of the data, applying a Hann window and taking a $4 \mathrm{~s}$ Fourier transform, and then plotting the received power in $\mathrm{dB} / \mathrm{uPa}^{2} / \mathrm{Hz}$. The received spectrograms show two types of arrivals. First, there is significant low frequency energy from 18 to $25 \mathrm{~Hz}$ with received levels on the order of $70 \mathrm{~dB}$ on $\mathrm{H} 11 \mathrm{~N} 1$ and $64 \mathrm{~dB}$ on H11N2. There are also broadband spikes, with occasionally substantially more energy. Note the very low noise levels. Ambient noise in the ocean at low frequencies is dominated by surface shipping traffic. Observations of $30 \mathrm{~dB} \mathrm{re} 1 \mathrm{uPa}^{2} / \mathrm{Hz}$ ambient noise at these frequencies are well below expected shipping levels from Wenz $(55 \mathrm{~dB}$ $\mathrm{re}_{\mathrm{uPa}} / \mathrm{Hz}$ ). (Wenz, 1962; Kewley et al., 1990). Clearly the location of Wake Island, and its significant distance from any commercial shipping lane, leads to very low noise levels and very high detection sensitivity.

Two results are clear from Fig. 2. The first is that the southern hydrophone is receiving less energy than the northern hydrophone. Averaged across the band, in the first hour there is $6 \mathrm{~dB}$ less energy arriving at the southern station compared to the northern station. The other observation is that the receptions on the two sites appear to be correlated. This will be quantified below. Given the differences in bathymetry, highlighted in Fig. 1, and the $138 \mathrm{~km}$ meridional offset of the two stations, this is unexpected.

In Fig. 3, 9 min of timeseries data for H11N1 and H11S1 is presented. During this $9 \mathrm{~min}$, beginning at 2009-0529T04:15:00Z, there are 3 large bursts of broadband energy. This signal is $15 \mathrm{~min}$ into the time period presented in Fig. 2. The northern station peaks arrival arrive $18 \mathrm{~s}$ later, corresponding to the travel time over the difference in geodesic distance of $29 \mathrm{~km}$. The H11S1 arrivals are approximately $6 \mathrm{~dB}$ lower than the H11N1 station to the north of Wake Island. Note the correlation between the two hydrophones for both initial single pulses and broader later arriving pulses.

The utility of the triplet array, with $2 \mathrm{~km}$ spatial separation in a triangle, is the ability to perform wide-band direction finding via time-delay-of-arrival TDOA processing. Standard processing of International Monitoring Station (IMS) data is performed using the Progressive MultiChannel Correlation (PMCC) algorithm developed by Cansi (1995) and has been applied to T-phase generation site localization (Graeber and Piserchia, 2004). This sophistication is not required here. In this situation, the array is small relative to source distance and the azimuthal ambiguity is broken by prior knowledge of the geometric sector of the source. The phone-to-phone correlation and bearing estimates are computed (averaged across element pairs). The acoustic timeseries are base banded to $10-50 \mathrm{~Hz}$ and broken into $1 \mathrm{~min}$ short time pings. These 1-min pings, $P_{i}(t)$, are then pair-wise cross-correlated using the standard normalized crosscorrelation function (Bendat and Piersol, 1999):

$$
C_{i j}(\Delta t)=\frac{\int P_{i}(t) P_{j}(t+\Delta t) d t}{\sqrt{\int\left|P_{i}(t)\right|^{2} d t \int\left|P_{j}(t)\right|^{2} d t}} .
$$

The pairwise cross-correlation is normalized by the power in each short-time window such that a perfect correlation gives unity. The peak delay-time is mapped to angle by the simple plane wave arrival formula

$$
\theta_{i j}(\Delta t)=\cos ^{-1}\left\{\frac{c \Delta t}{d_{i j}}\right\}
$$

This analysis is applied to the northern triplet, the southern triplet and then to the combination of northern and southern hydrophones. The results using the same time period shown in Fig. 2 for correlation and bearing estimation are shown in Fig. 4 below.

The pairwise cross-correlations for the northern triplet H11N1-N3 are shown in the upper row of Fig. 4. For the first $2 \mathrm{~h}$ the correlation ranges from greater than 0.8 to 0.35 . Note in Fig. 2 that in the second $2 \mathrm{~h}$ of data there are large broadband

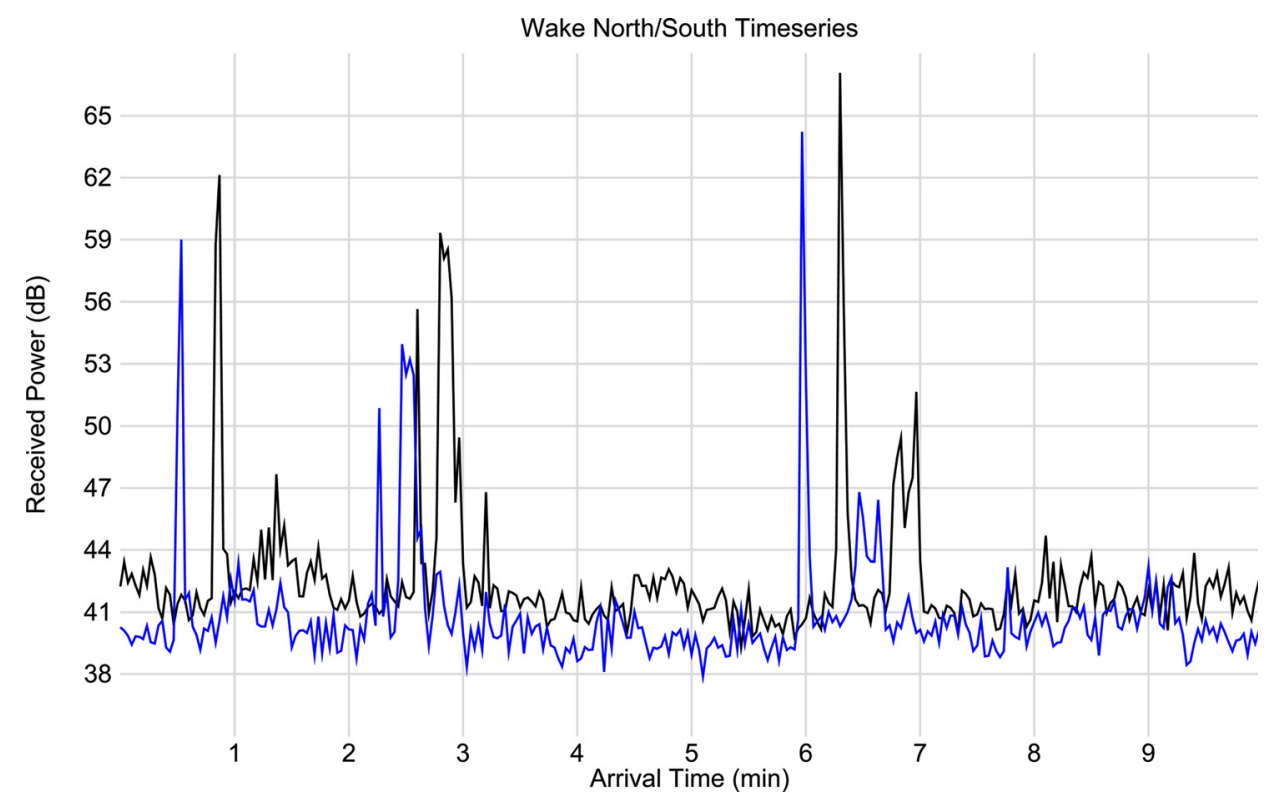

FIG. 3. (Color online) Bandpassed $(10-50 \mathrm{~Hz})$ broadband arrivals from the Sarigan eruption event on phone H11N1 (dark) and H11S1(light). Received power is in $\mathrm{dB}$ re $1 \mu \mathrm{Pa}^{2}$. The southern arrivals are $4-10 \mathrm{~dB}$ lower and arrive $18 \mathrm{~s}$ earlier. Again note the very high correlation between the two hydrophones. 

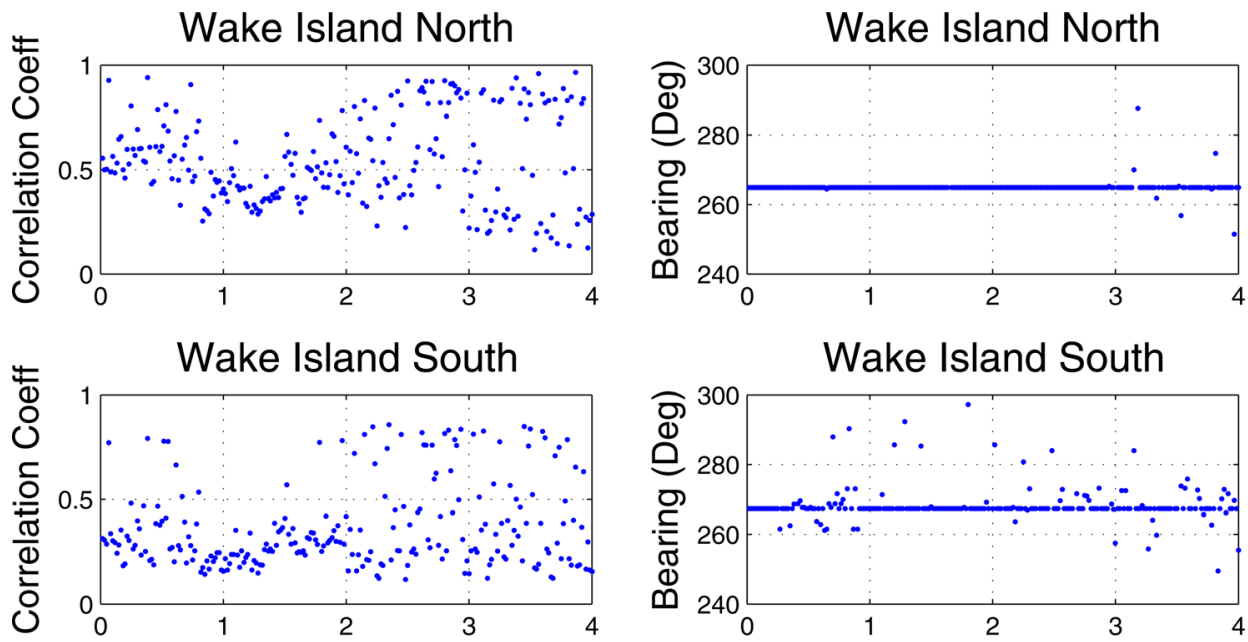

FIG. 4. (Color online) Pairwise 1-min time-domain (left) cross-correlation results and (right) bearing estimation for the (top) Northern triplet, (middle) Southern triplet and (bottom) combined northern/southern. The geodesic arrival angle from the seamount to $\mathrm{H} 11 \mathrm{~N} 1$ is $264.6^{\circ}$ and to $\mathrm{H} 11 \mathrm{~S} 1$ is
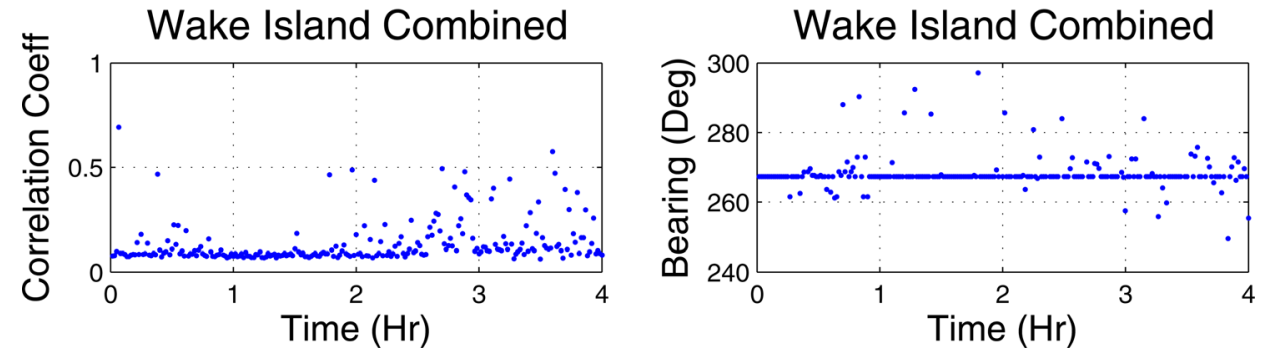
$267.8^{\circ}$

bursts visible on both sets of hydrophones. If these signals were not from Sarigan, the bearing estimation would be expected to be noisy, which it is not. The geodesic arrival angle for this path is $264.6^{\circ}$, which is within half a degree of the peak picked by H11N1-N2 and H11N2-N3. The middle row of Fig. 4 shows the pairwise cross-correlations and bearing estimates for the southern triplet (H11S1-S3). The correlation is lower than the northern triplet, on the order of 0.3 , presumably due to lower signal level and poor SNR. The estimate bearing of the arrival very closely matches the predicted geodesic of $267.8^{\circ}$. The lower panel presents the most surprising result of all. The correlation between northern phone 1 (H11N1) and the southern triplet (H11S1-S3) shows a correlation of roughly 0.1 and the bearing estimate has a clear observed peak at $266^{\circ}$. In spite of the bathymetric differences in the two paths, and the $138 \mathrm{~km}$ offset in latitude, there is an observable correlation between the two pairs of stations.

\section{TWO DIMENSIONAL AND THREE DIMENSIONAL ADIABATIC MODE PARABOLIC EQUATION MODELING RESULTS}

A propagation modeling study of the Sarigan seamount to Wake Island CTBTO Stations is now presented. Basin scale acoustic propagation has been studied using many approaches. The 2D approaches include horizontal rays (Jensen et al., 1997), vertical acoustic adiabatic normal modes (Jensen et al., 1997), and Nx2D Parabolic Equation (Collins, 1993a). Several 3D acoustic approaches include hybrid vertical adiabatic modes-horizontal rays (Weinburg and Burridge, 1974; Heaney et al., 1991) and hybrid vertical adiabatic modes-parabolic equation (Collins, 1993b). The primary physics phenomena of interest in the vertical are sound speed profile with depth and bathymetric scattering. In the horizontal, at long ranges, refraction from horizontal sound speed gradients, the non-spherical geoid of the earth, and bathymetry scattering, refraction and diffraction are important. In this paper, we are primarily interested in bathymetric forward scattering and blockage so an $\mathrm{Nx} 2 \mathrm{D} \mathrm{PE}$ model is used. Open ocean seamounts have large slopes $\left(\sim 15^{\circ}\right)$ and propagation up, over and down is not expected to be adiabatic (McDonald et al., 1994). The PE handles this severe range-dependence. The impact of 3D acoustics is demonstrated by the application of the hybrid Adiabatic Mode PE (AMPE).

A parabolic equation model based upon the RAM splitstep Pade Parabolic Equation (Collins, 1993a) was applied to this environment, computing the range-dependent acoustic field using an Nx2D approach. This approach is expected to have propagation effects such as mode coupling and attenuation (mode-stripping) due to propagation over shallow seamounts. It will not have out-of-plane 3D effects such as diffraction around a boundary or refraction/reflection due to azimuthal variability in the environment. A propagation frequency of $18 \mathrm{~Hz}$ was chosen to match the dominant lowfrequency arrival of the observation. The plan-view Transmission Loss for a source at the Sarigan Seamount location is shown in Fig. 5. The level plotted is the magnitude squared pressure averaged over $500-1000 \mathrm{~m}$ in depth, plotted in $\mathrm{dB}\left(10 \log P^{2}\right)$. There are geodesic spokes where complete blockage due to a seamount or island is visible, as well as others where partial blockage is due to a submerged seamount.

The vertical slices along the geodesic between the Sarigan seamount and H11N1 and H11S1 are shown in Fig. 6. 


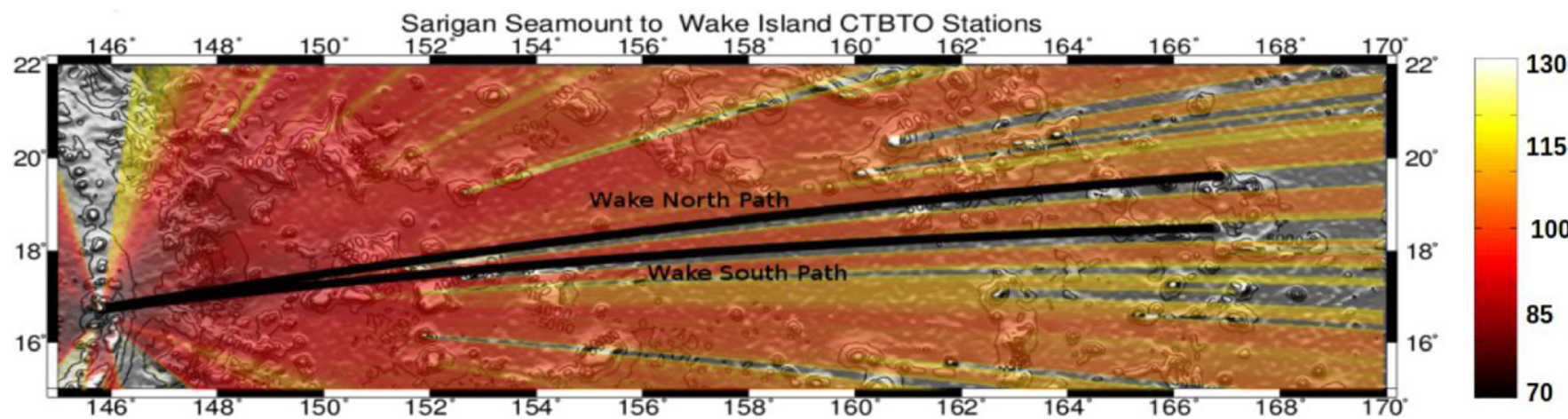

FIG. 5. (Color online) Nx2D Parabolic Equation model results of Transmission Loss for the Sarigan Seamount location. The TL dynamic range is $70-130$ dB. The frequency is $18 \mathrm{~Hz}$ and the TL is averaged (in power) in depth from 500 to $1000 \mathrm{~m}$. The paths to the northern triplet and southern triplet are shown in black. Note the blockage of the southern path.

Both paths encounter significant bathymetry near the source, as they cross the submerged ridge located at $148^{\circ} \mathrm{E}$ (see Fig. 5). The northern path (upper panel) contains bathymetric features extending up into the water column at $500 \mathrm{~km}$ and $1800 \mathrm{~km}$. Note the scattering toward the surface at $500 \mathrm{~km}$ and the mode stripping that occurs with each seamount interaction. The southern path (lower panel) encounters axial seamounts $(\sim 1500 \mathrm{~m})$ as well as a seamount that extends nearly to the surface. The minimum depth of the path over the seamount at a range of $750 \mathrm{~km}$ is $30 \mathrm{~m}$. The acoustic path propagates over very shallow water for $10 \mathrm{~km}$. In order to see that the acoustic field is not completely cut off, the dynamic range of the plot has been increased to $70-150 \mathrm{~dB}$. The minimum Transmission Loss at the receiver
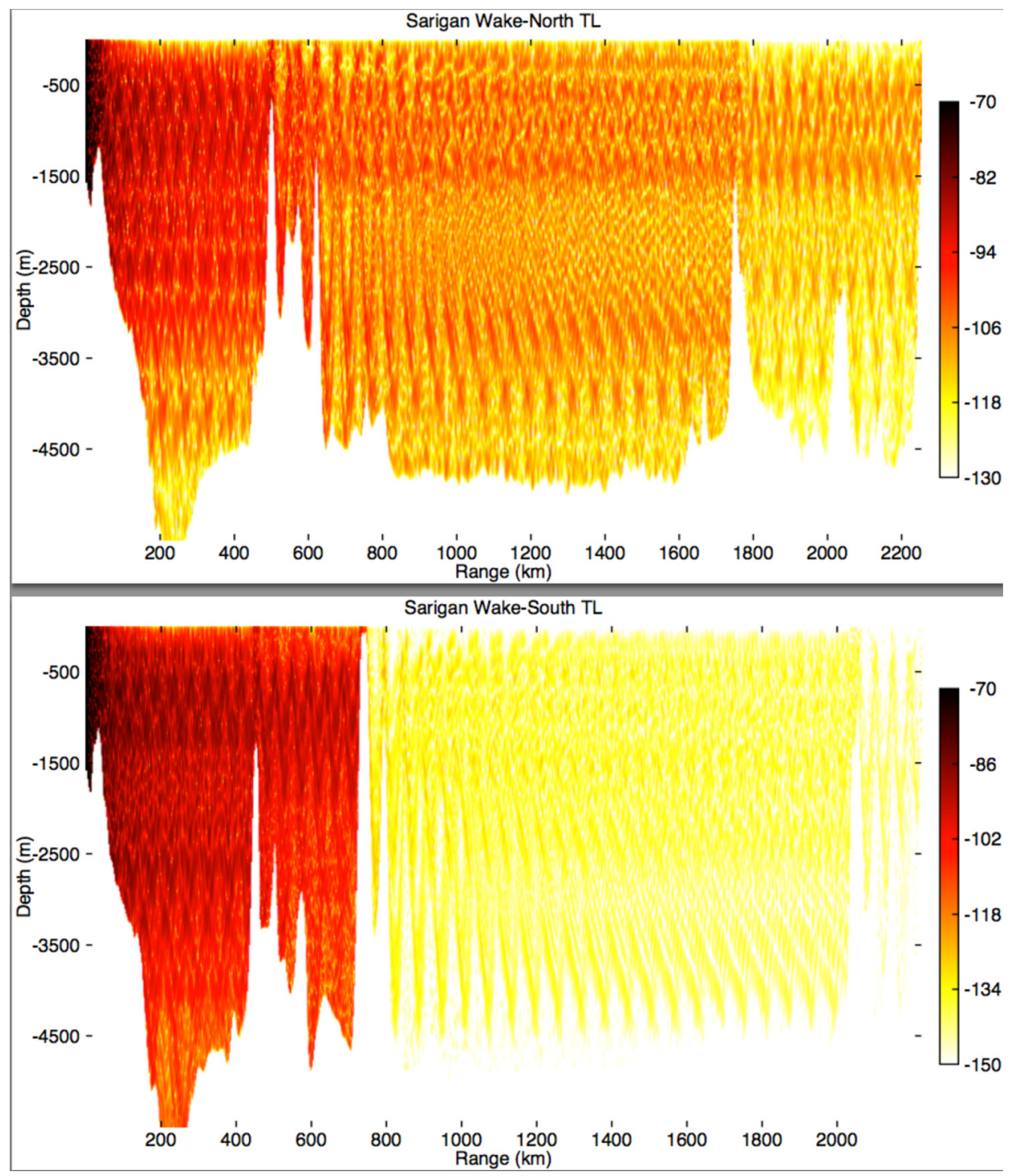

FIG. 6. (Color online) Narrowband $(18 \mathrm{~Hz})$ Transmission Loss along geodesic from Sarigan to (top) H11N1 and (bottom) H11S1. The bathymetry is plotted as a solid line. The dynamic range is $70-130 \mathrm{~dB}$ in the upper and $70-150 \mathrm{~dB}$ in the lower. This change in scale is required to see that the seamount at range $780 \mathrm{~km}$ nearly, but not completely, blocks the transmission. The predicted difference in received level is on the order of $60 \mathrm{~dB}$. 


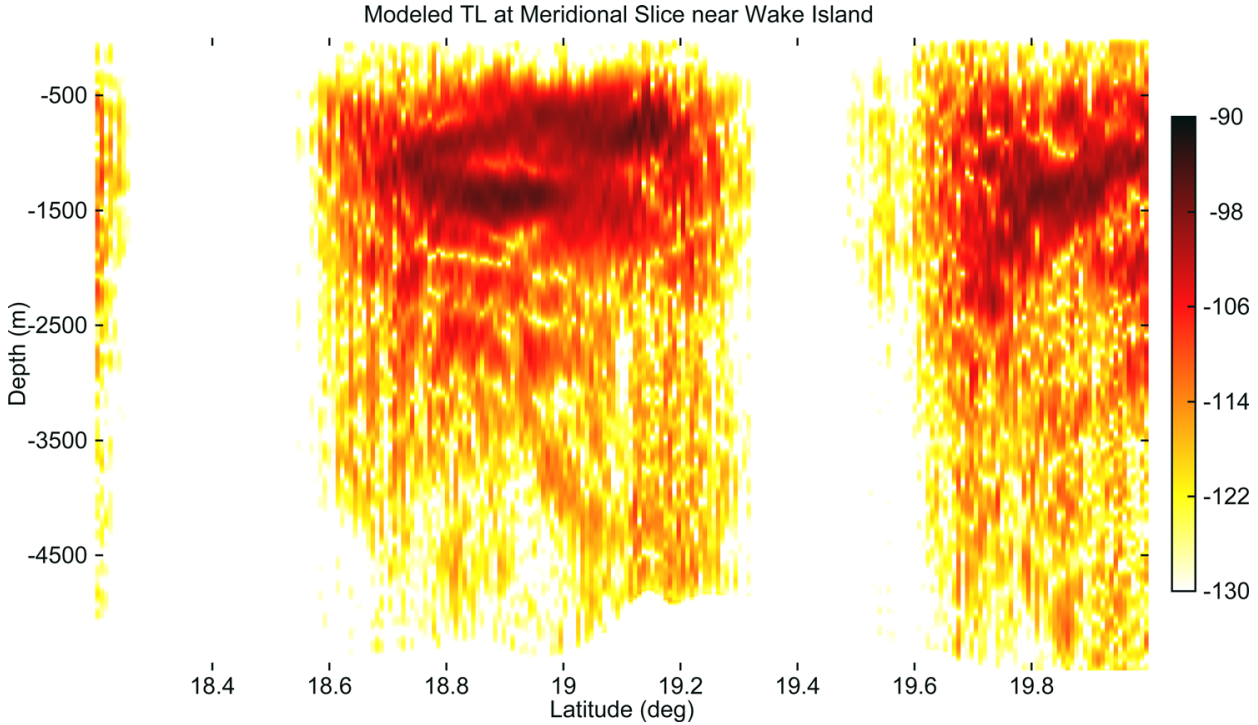

FIG. 7. (Color online) Nx2D modeled meridional Transmission Loss along $166.2^{\circ} \mathrm{E}$, from 18.3 to $20.0^{\circ} \mathrm{N}$. The southern triplet is at $18.51^{\circ} \mathrm{N}$ in the middle of the seamount blockage. The dynamic range is $90-130 \mathrm{~dB}$. The northern triplet is at latitude $19.71^{\circ} \mathrm{N}$, well within the unblocked portion. At $18.8^{\circ} \mathrm{N}$, there is a more open path with clear mode 2 arriving energy. is $164 \mathrm{~dB}$, compared with $107 \mathrm{~dB}$ for the northern path. This result is sensitive to geoacoustic parameters of the seamount. A 60 -m homogenous sediment of silt (grain size parameter $\phi=5$ ) overlays a basalt basement. Basalt is a challenge to model in the fluid-fluid model used here. Measurements have been taken off of the volcanic island of Hawaii and it was shown that the basalt was very attenuative (Heaney, 2005). Shear loss is not modeled, but is approximated by a high attenuation in the basement. Thinner sediment or a harder sediment (sand, rock) lead to complete cut-off of energy. Although the PE does not predict complete blockage for this sediment, the northern and southern paths are shown by the model to have a $60 \mathrm{~dB}$ difference in TL. This is in clear disagreement with the observations, where the received energy on the southern triplet array is on average $6 \mathrm{~dB}$ lower than for the northern array.

To examine the horizontal extent of the acoustic shadow, in the limit of only in-plane propagation (Nx2D), the full-water column acoustic field is computed for a meridional slice at longitude $166.8^{\circ} \mathrm{E}$. The results are shown in Fig. 7. Open water paths are visible from $18.2^{\circ} \mathrm{N}$ to $19.3^{\circ} \mathrm{N}$ and beyond $19.6{ }^{\circ} \mathrm{N}$. The $\mathrm{H} 11 \mathrm{~N} 1$ receiver is located at $19.71^{\circ} \mathrm{N}$, which has significant energy on this plot, although less than for the most open water path at $18.8^{\circ} \mathrm{N}$. The $\mathrm{H} 11 \mathrm{~S} 1$ receiver, located at $18.51^{\circ} \mathrm{N}$ is in the middle of a seamount shadow.

The discrepancy between the observations and the acoustic model reveals a major flaw in the Nx2D modeling assumptions. The vertical aspect of the acoustic computation, though sensitive to geo-acoustics, is well handled by the parabolic equation. The in-plane propagation assumption, neglecting horizontal effects is clearly inadequate. Three out-of-plane mechanisms must be considered (Munk et al., 1988). Horizontal refraction due to bathymetric interaction would increase the horizontal extent of the shadow zone and is not a mechanism for increasing the observed energy behind the seamount. Wave diffraction will lead to healing of the acoustic shadow. This was observed experimentally from a seamount scattering experiment in the central Pacific in 2004 (Heaney et al., 2005; Sikora, 2009). The final mechanism to be considered is the direct reflection from sharp bathymetric features can fill in shadow zones.

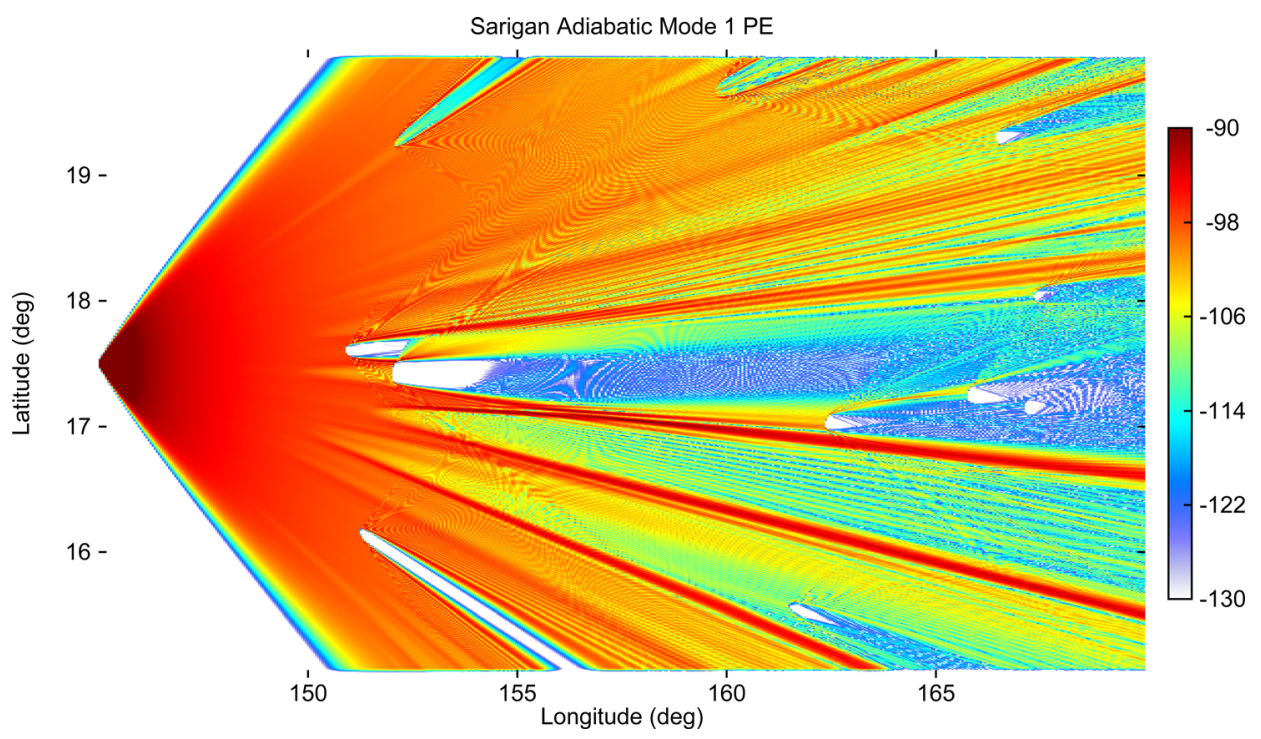

FIG. 8. (Color online) Adiabatic Mode Parabolic Equation (AMPE) Transmission Loss solution for $18 \mathrm{~Hz}$ from the Sarigan Volcano site east to Wake Island. Significant 3D effects of reflection and diffraction from shallow seamounts (guyots) are evident. 
Diffraction behind a blockage, refraction and scattering are well-known 3D wave propagation phenomena. To demonstrate that $3 \mathrm{D}$ propagation does explain the observations the adiabatic mode PE (Collins, 1993b; Heaney et al., 2012) for mode 1 is applied to the Sarigan problem. The $18 \mathrm{~Hz}$ mode-1 phase speeds are computed as a function of water depth using the analytical solution for a rigid bottom. The Split-Step Pade propagator is then applied to the acoustic field to compute the mode 1 amplitude as a function of range and cross-range. The field is multiplied by the mode-1 eigenfunction at the axis (squared) to compute Transmission Loss. Note that the cylindrical spreading term (divide by $\sqrt{r}$ ) is not applied in this computation. Absorbing boundaries are placed at the northern and southern boundaries to prevent reflections. It was found that the result was sensitive to the resolution of the phase speed computation. It was found that the phase speed computation was required to be performed on the PE grid spacing, rather than on the much lower bathymetric resolution and then interpolated in phase speed within the PE. This is a result of the very nonlinear behavior of the eigenvalue computation as the bathymetry shoals and approaches the cutoff depth. The mode 1 Transmission Loss, not in an equidistant projection, is shown below in Fig. 8. The conical shape of the outgoing energy is due to the reduced high-angle support of the PE. Three-dimensional effects of diffraction and scattering are clearly visible.

To examine the predicted received energy level difference between an Nx2D and 3D propagation, the TL is compared along the Meridional slice shown in Fig. 7. The Nx2D TL from Fig. 7 is averaged (in pressure squared) from 500 to $2000 \mathrm{~m}$ to generate an approximate Nx2D axial TL. The comparison with the AMPE mode $1 \mathrm{TL}$ is shown in Fig. 9. The deep, greater than $25 \mathrm{~dB}$, acoustic shadows are not present in the $3 \mathrm{D}$ computation. For the AMPE solution, the southern receivers are predicted to have a transmission loss of $\sim 110 \mathrm{~dB}$ compared with $103 \mathrm{~dB}$ for the northern receivers. This $5-10 \mathrm{~dB}$ difference in arrival level is entirely consistent with the observations. It is therefore concluded that Nx2D propagation is insufficient to model the observations and 3D acoustics is required.

\section{SUMMARY AND CONCLUSION}

On 29 May 2010, there was an observed undersea volcanic eruption south of the island of Sarigan in the Mariana Island chain. Acoustic energy from this event was recorded on a pair of hydrophone arrays deployed by the Comprehensive Test Ban Treaty Organization north and south of Wake Island, a distance of $2250 \mathrm{~km}$ from Sarigan. Each array is a triplet of axial hydrophones arranged in a triangle with an inter-element spacing of approximately $2 \mathrm{~km}$. The arrivals consisted of low-frequency rumbling $(18-25 \mathrm{~Hz})$ and broadband spikes. The received levels on the southern triplet were $6 \mathrm{~dB}$ lower than those observed on the northern triplet. Cross correlation processing and Time-Delay-of-Arrival (TDOA) processing were performed for each of the six hydrophones to produce bearing estimates. Both arrays produced estimated angles of arrivals very close to the computed geodesic arrival angles. The southern station had more noise in the estimation due to a lower signal-to-noise ratio. Correlation processing between phones from the north and south triplets, separated by $138 \mathrm{~km}$, produce reliable bearing estimates as well, indicating stable correlation for the two paths.

Two-dimensional acoustic modeling using the Parabolic Equation (PE) was performed for the Sarigan seamount eruption event. There are a large number of seamounts in the

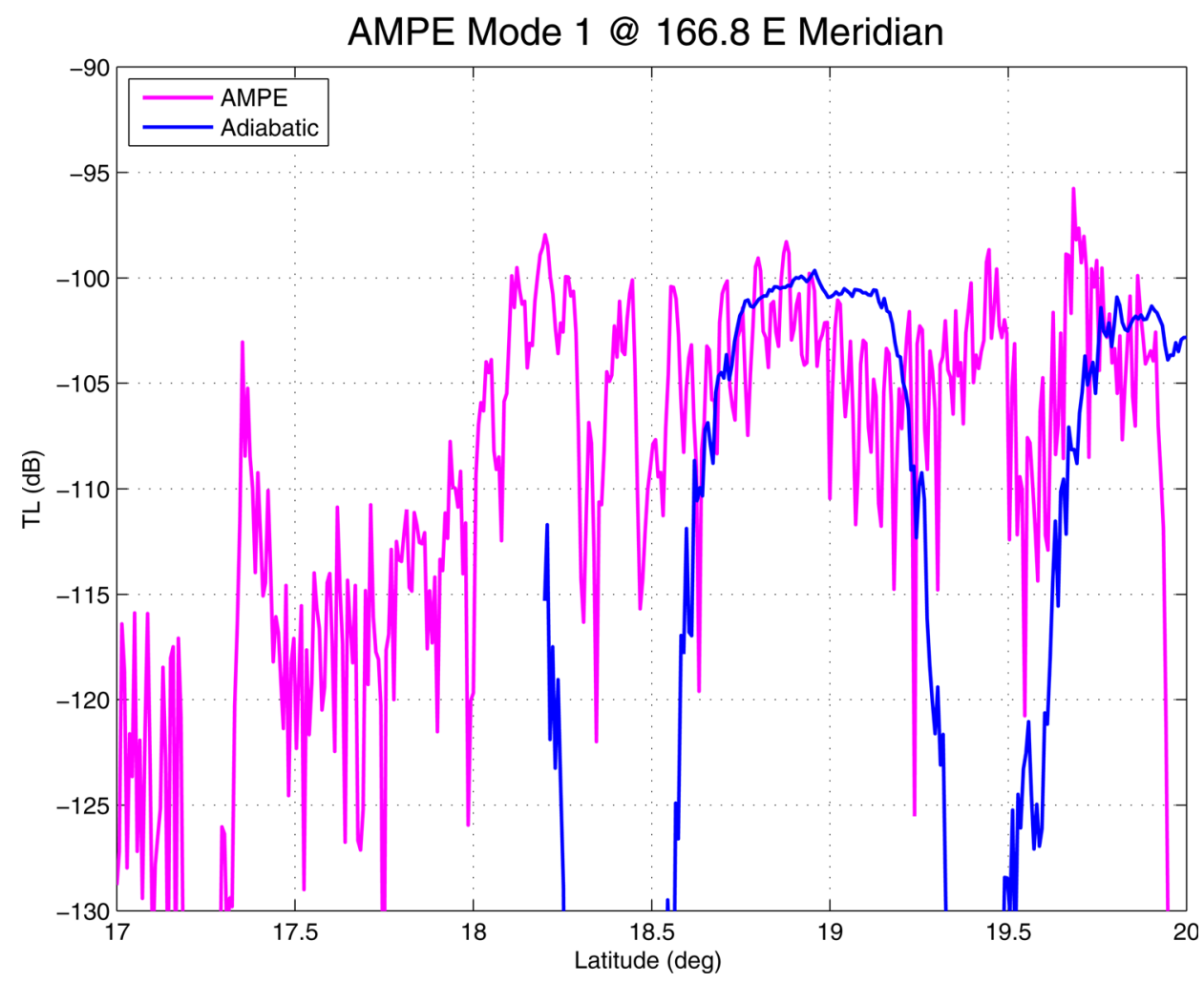

FIG. 9. (Color online) Nx2D and 3D modeled meridional Transmission Loss along $166.8^{\circ} \mathrm{E}$, from $17^{\circ}$ to $20.0^{\circ} \mathrm{N}$. The southern triplet is at $18.5^{\circ} \mathrm{N}$ in the middle of the seamount blockage. The northern triplet is at latitude $19.72^{\circ}$, well within the unblocked portion. The 3D TL prediction has significant energy at $18.5^{\circ} \mathrm{N}$. 
region. The Sarigan to northern station path crosses several seamounts with minimum depths of $800 \mathrm{~m}$. The southern geodesic, however, crosses a seamount with a minimum depth of $30 \mathrm{~m}$. The PE model, with an optimistic sediment of silt over basalt, predicts a $60 \mathrm{~dB}$ difference between the two paths. This is predicted as an almost complete blockage. This result is inconsistent with the observations, challenging the assumption that propagation is $2 \mathrm{D}$. There is the possibility that the conversion of acoustic energy to shear in the seamount and then reconversion back into acoustic energy (T-phase) is happening. We reject this mechanism because the volume loss of shear in rock is substantial.

Horizontal refraction, scattering from the Sarigan Island and wave diffraction are 3D mechanisms that can fill in the acoustic shadow. Three-dimensional propagation filling of the seamount acoustic shadow is demonstrated by the computation of a mode-1 Adiabatic Mode PE acoustic field. The 3D AMPE result predicts a 5-10 dB difference between the northern site and the southern site, consistent with observations.

Bendat, J. S., and Piersol, A. G. (1999). Measurement and Analysis of Random Data (John Wiley and Sons, New York), 64 pp.

Cansi, Y. (1995). "An automatic seismic event processing for detection and localization: The P.M.C.C. method," Geophys. Res. Lett. 22, 1021-1024, doi:10.1029/95GL00468.

Collins, M. (1993a). "A split-step Pade solution for the parabolic equation method," J. Acoust. Soc. Am. 93, 1736-1742.

Collins, M. D. (1993b). “The adiabatic mode parabolic equation," J. Acoust. Soc. Am. 94, 2269-2278.

DeGroot-Hedlin, C., and Orcutt, J. (2001). "Monitoring the comprehensive nuclear-test-ban treaty," Pure Appl. Geophys. 158, 421-626.

Graeber, F. M., and Piserchia, P.-F. (2004). "Zones of T-wave excitation in the NE Indian ocean mapped using variations in back azimuth over time obtained from multi-channel correlation of IMS hydrophone triplet data," Geophys. J. Int. 158, 239-256.

Hanson, J., Le Bras, R., Dysart, P., Brumbaugh, D., and Gault, A. (2001). "Operational processing of hydroacoustic data at the Prototype International Data Center," Pure Appl. Geophys. 158, 425-456.
Heaney, K. D. (2005). "The Kauai Near-Source Test (KNST): modeling and measurements of downslope propagation near the NPAL Kauai source," J. Acoust. Soc. Am. 117, 1635-1642.

Heaney, K. D., Baggeroer, A. B., Becker, K. M., Scheer, E., and Vonderheydt, K. (2005). "Range Dependent Propagation off a Seamount (BASSEX 04)," in Underwater Acoustic Measurements 2011, edited by J. S. Papadakis, and L. Bjorno (IACM, F.O.R.T.H., Crete, Greece), pp. $1237-1242$.

Heaney, K. D., Campbell, R. L., and Murray, J. J. (2012). "Comparison of hybrid three-dimensional modeling with measurements on the continental shelf," J. Acoust. Soc. Am. 131, 1680-1688.

Heaney, K. D., Kuperman, W. A., and McDonald, B. E. (1991). "PerthBermuda sound propagation (1960): Adiabatic mode interpretation," J. Acoust. Soc. Am. 90, 2586-2594.

Jensen, F. B., Kuperman, W. A., Porter, M. B., and Schmidt, H. (1997) Computational Ocean Acoustics (American Institute of Physics Press, New York, USA), 611 pp.

Kewley, D. J., Browning, D. G., and Carey, W. M. (1990). "Low-frequency wind-generated ambient noise source levels," J. Acoust. Soc. Am. 88, 1894-1902.

McDonald, B. E., Collins, M. D., Kuperman, W. A., and Heaney, K. D. (1994). "Comparison of data and model predictions for Heard Island acoustic transmissions," J. Acoust. Soc. Am. 96, 2357-2370.

Munk, W., O'Reilly, W. C., and Reid, J. L. (1988). "Australia-Bermuda Sound Transmission Experiment (1960) Revisited,” J. Phys. Oceanogr. 18, 1876-1898.

Prior, M. K., Chapman, R., and Newhall, A. (2012). "The long-range detection of an accidental underwater explosion," in European Conference on Underwater Acoustics (Edinburgh, Scotland, UK).

Sikora, J. J. (2009). "Sound propagation around underwater seamounts," in Ocean Engineering (Massachusetts Institute of Technology and the Woods Hole Oceanographic Institution, Boston, MA), 189 pp.

Snellen, M., Evers, L., and Simons, D. G. (2011). "Modeling the long-range acoustic propagation for the May 2010 Sarigan volcano eruption," in Underwater Acoustics Measurements, edited by J. S. Papadakis (Kluwer, Kos, Greece), pp. 1361-1368.

U.S. Geological Survey (2010). "Smithsonian/USGS Weekly Volcanic Activity Report, 9 June 2010," (U.S. Geological Survey, Washington, DC).

Weinburg, H., and Burridge, R. (1974). "Horizontal ray theory for ocean acoustics," J. Acoust. Soc. Am. 55, 63-79.

Wenz, G. M. (1962). "Acoustic ambient noise in the ocean: spectra and sources," Journal of the Acoustical Society of America 34, 1936-1956. 